\title{
Article \\ Study on Performance Improvements in Perovskite-Based Ultraviolet Sensors Prepared Using Toluene Antisolvent and $\mathrm{CH}_{3} \mathrm{NH}_{3} \mathrm{Cl}$
}

\author{
Seong Gwan Shin $\mathbb{D}$, Chung Wung Bark $\mathbb{D}$ and Hyung Wook Choi * \\ Department of Electrical Engineering, Gachon University, 1342 Seongnam Daero, Seongnam-Si 13120, Korea; \\ 1020days@gmail.com (S.G.S.); bark@gachon.ac.kr (C.W.B.) \\ * Correspondence: chw@gachon.ac.kr; Tel.: +82-31-750-5562
}

check for updates

Citation: Shin, S.G.; Bark, C.W.; Choi, H.W. Study on Performance Improvements in Perovskite-Based Ultraviolet Sensors Prepared Using Toluene Antisolvent and $\mathrm{CH}_{3} \mathrm{NH}_{3} \mathrm{Cl}$. Nanomaterials 2021, 11, 1000. https:// doi.org/10.3390/nano11041000

Academic Editor: Alexey Pestryakov

Received: 20 March 2021

Accepted: 10 April 2021

Published: 13 April 2021

Publisher's Note: MDPI stays neutral with regard to jurisdictional claims in published maps and institutional affiliations.

Copyright: (c) 2021 by the authors. Licensee MDPI, Basel, Switzerland. This article is an open access article distributed under the terms and conditions of the Creative Commons Attribution (CC BY) license (https:// creativecommons.org/licenses/by/ $4.0 /)$.

\begin{abstract}
In this study, a simply structured perovskite-based ultraviolet C (UVC) sensor was prepared using a one-step, low-temperature solution-processing coating method. The UVC sensor utilized $\mathrm{CH}_{3} \mathrm{NH}_{3} \mathrm{PbBr}_{3}$ perovskite as the light-absorbing layer. To improve the characteristics of $\mathrm{CH}_{3} \mathrm{NH}_{3} \mathrm{PbBr}_{3}$, an antisolvent process using toluene and the addition of $\mathrm{CH}_{3} \mathrm{NH}_{3} \mathrm{Cl}$ were introduced. The device with these modifications exhibited a response rise/fall time of 15.8/16.2 ms, mobility of $158.7 \mathrm{~cm}^{2} / \mathrm{V} \cdot \mathrm{s}$, responsivity of $4.57 \mathrm{~mA} / \mathrm{W}$, detectivity of $1.02 \times 10^{13}$ Jones, and external quantum efficiency of $22.32 \%$ under the 254-nm UV illumination. Therefore, this methodology could be a good approach in facilitating UVC detection.
\end{abstract}

Keywords: ultraviolet (UV) sensors; bandgap widening; $\mathrm{CH}_{3} \mathrm{NH}_{3} \mathrm{PbBr}_{3}$; antisolvent; $\mathrm{CH}_{3} \mathrm{NH}_{3} \mathrm{Cl}$

\section{Introduction}

Ultraviolet (UV) sensors have received significant research interest owing to their promising applications in communications, image sensing, environmental monitoring, astronomy, and medicine [1-5]. The UV range can be divided into three areas depending on the wavelength range, of UVA (320-400 nm), UVB (280-320 nm), and UVC (100-280 nm). Of the UV rays emitted by the sun, most UVA radiation reaches the Earth's surface, most UVB is absorbed by the ozone layer with only a small amount reaching the surface, and UVC is completely absorbed by the ozone layer and atmosphere and does not reach the Earth surface.

While UVC is rare on the surface of the Earth, it can be emitted from lightning strikes or artificial sources such as arc welding, mercury lamps, and UV sterilization lamps. Even extremely low exposure to UVC can have a detrimental effect on the human body. The short-wavelength UV rays of less than $300 \mathrm{~nm}$ do not penetrate the epidermis when they touch the skin. However, long-wavelength UV rays have a strong penetrating power and can adversely affect the skin, eyes, and immune system, and are considered as harmful to the human body. Because UV rays are invisible to human vision, many safety accidents are caused by exposure to UV rays at industrial sites.

In addition, when the insulation levels of high-voltage transmission lines and transformers have deteriorated, power loss can occur via arc discharge. With continuous discharge, the insulating facility deteriorates further and the power system is destroyed; thus, large-scale power failure may occur.

Therefore, it is essential to develop semiconductor-based optical sensor systems that can convert incident radiation signals into electrical signals. In general, semiconductorbased sensors employ two detection methods. The first method uses a semiconductor with a wide bandgap, such as $\mathrm{AlGaN}, \mathrm{MgZnO}, \mathrm{Ga}_{2} \mathrm{O}_{3}, \mathrm{ZnGa}_{2} \mathrm{O}_{4}, \mathrm{MoS}_{2}$, or diamond. However, these materials require high-temperature and expensive processing methods, such as molecular beam epitaxy, chemical vapor deposition, pulsed laser deposition, atomic layer 
deposition, and magnetron sputtering [6-10]. The second detection method uses a narrowbandgap Si diode sensor equipped with a UV filter. However, the high-performance UVC detection is difficult to achieve with Si diodes, because photogenerated carriers cannot easily reach the depletion layer of the semiconductor.

Recently, organic-inorganic perovskites have received much attention in radiation emission and detection, including solar cell applications. The high-quality perovskite crystals can be grown easily using a simple cold-solution method. The perovskite thin films coated by a simple low-temperature solution method can be uniform with good pinhole control by increasing the nucleus density of the perovskite through an antisolvent process. In addition, when $\mathrm{Br}^{-}$ions are substituted with $\mathrm{Cl}^{-}$, the bandgap increases. Perovskites have a large absorption coefficient of approximately $10^{5} \mathrm{~cm}^{-1}$ in the UVC spectral range, as well as high mobility. Therefore, perovskite materials are expected to show high sensitivity and fast UVC response performance in UVC detection sensors when used with UV filters. However, the use of perovskites for UVC detection has rarely been reported. With the addition of an antisolvent process, a uniform and pinhole-controlled film can be manufactured, and by adding $\mathrm{CH}_{3} \mathrm{NH}_{3} \mathrm{Cl}$, the bandgap is adjusted, resulting in improved UVC performance.

In this study, a $\mathrm{CH}_{3} \mathrm{NH}_{3} \mathrm{PbBr}_{3}$ thin film was fabricated on an etched indium-doped tin oxide (ITO) electrode using a one-step process to form a perovskite film-based UV sensor. To improve the surface of the prepared $\mathrm{CH}_{3} \mathrm{NH}_{3} \mathrm{PbBr}_{3}$ thin film and control the bandgap, a UVC sensor with a simple structure was fabricated through an antisolvent process with the addition of $\mathrm{CH}_{3} \mathrm{NH}_{3} \mathrm{Cl}$. Consequently, the modified $\mathrm{CH}_{3} \mathrm{NH}_{3} \mathrm{PbBr}_{3}$ thin film exhibited improved surface properties, bandgap control, and mobility compared to those of the bare $\mathrm{CH}_{3} \mathrm{NH}_{3} \mathrm{PbBr}_{3}$. In addition, the perovskite-based UVC sensor exhibited a responsiveness of $4.57 \mathrm{~mA} / \mathrm{W}$, detectability of $1.02 \times 10^{13}$ Jones, and an external quantum efficiency (EQE) of $22.32 \%$ under the 254-nm UV illumination. Besides, the simply structured UVC sensor fabricated using a low-temperature solution process showed high detectivity. The reported perovskite-based UVC sensors yield improved UVC sensing using materials with potential for further development.

\section{Materials and Methods}

\subsection{Materials}

Lead(II) bromide ( $\mathrm{PbBr}_{2}, 99.999 \%$ trace metals basis), $\mathrm{N}, \mathrm{N}$-dimethylformamide (DMF, $99.8 \%$ ), toluene $(99.8 \%)$, and dimethyl sulfoxide (DMSO, 99.7\%) were purchased from Sigma Aldrich (Saint Louis, MO, USA). Methylammonium bromide $\left(\mathrm{CH}_{3} \mathrm{NH}_{3} \mathrm{Br}, \mathrm{MABr}\right)$ and methylammonium chloride $\left(\mathrm{CH}_{3} \mathrm{NH}_{3} \mathrm{Cl}, \mathrm{MACl}\right)$ were obtained from GreatCell Solar (Queanbeyan, Australia). ITO deposited on a quartz glass substrate with a thickness of $150 \mathrm{~nm}$ was obtained from RND Korea (Gwangmyeong, Korea). AZ GXR-601 photoresist (PR) and AZ 300 MIF were obtained from AZ Electronic Materials (Wiesbaden Germany). All materials were used without further purification.

\subsection{Preparation of ITO}

The quartz glass on which ITO was deposited was washed with distilled water, acetone, and 2-propanol for 20 min each with an ultrasonic cleaner. The washed ITO glass was then dried in nitrogen and $50 \mu \mathrm{L}$ of AZ GXR-601 solution was spin-coated onto the dried substrate at $4000 \mathrm{rpm}$ for $60 \mathrm{~s}$. The coated PR solution was fired at $95^{\circ} \mathrm{C}$ for $1 \mathrm{~min}$ and then cooled to room temperature. Subsequently, UV irradiation was performed for $100 \mathrm{~s}$ in an exposure machine using a patterned photomask. After the exposure process was completed, the ITO glass was immersed in AZ 300 MIF to remove the part exposed to UV, and then fired at $120^{\circ} \mathrm{C}$ for $1 \mathrm{~min}$ and cooled to room temperature. The ITO was etched using an ITO etching solution and washed with acetone and distilled water to remove the AZ GXR-601 residue. 


\subsection{Synthesis of Perovskite}

The $\mathrm{MAPbBr}_{3}$ solution was mixed using a 1:1 molar ratio of $\mathrm{PbBr}_{2}$ to $\mathrm{MABr}$, and $100 \mu \mathrm{L}$ of DMSO was added and mixed in $1 \mathrm{~mL}$ of DMF. The mixture was stirred at room temperature for $6 \mathrm{~h}$. After stirring, the solution was filtered through a $0.45-\mu \mathrm{m}$ syringe filter just before coating. In the solution to which $\mathrm{MACl}$ was added, $\mathrm{PbBr}_{2}, \mathrm{MABr}$, and $\mathrm{MACl}$ were dissolved in $1 \mathrm{~mL}$ of DMF at molar ratios of 1:1:0.05-0.20 (in 0.05-M increments), respectively, and $100 \mu \mathrm{L}$ of DMSO was added. The resulting solution was stirred at room temperature for $6 \mathrm{~h}$. The stirred solution was filtered through a $0.45-\mu \mathrm{m}$ syringe filter just before coating and use.

\subsection{Preparation of a UV Sensor Based on Perovskite Films}

To fabricate the perovskite sensor, an etched quartz ITO substrate was first washed in distilled water, acetone, and 2-propanol with ultrasonic waves for 20 min each. After removing the residue by blowing nitrogen on the washed substrate, it was dried for $30 \mathrm{~min}$ at $80^{\circ} \mathrm{C}$ in a dryer. Polyimide tapes were attached to both ends of the dried ITO substrate to expose the electrodes. To prepare the $\mathrm{MAPbBr}_{3}$ thin film, $50 \mu \mathrm{L}$ of the $\mathrm{MAPbBr}_{3}$ solution was dropped onto the etched ITO substrate and spin-coated at $3000 \mathrm{rpm}$ for $45 \mathrm{~s}$. In order to introduce an antisolvent process, $\mathrm{MAPbBr}_{3}$ was coated by dropping $60 \mu \mathrm{L}$ of toluene for $25 \mathrm{~s}$ during coating. The coated $\mathrm{MAPbBr}_{3}$ thin film was fired at $140{ }^{\circ} \mathrm{C}$ for $15 \mathrm{~min}$ and then cooled to room temperature. For comparison, a bare sample without the antisolvent processing was also produced. A schematic of the fabricated device is shown in Figure 1a.
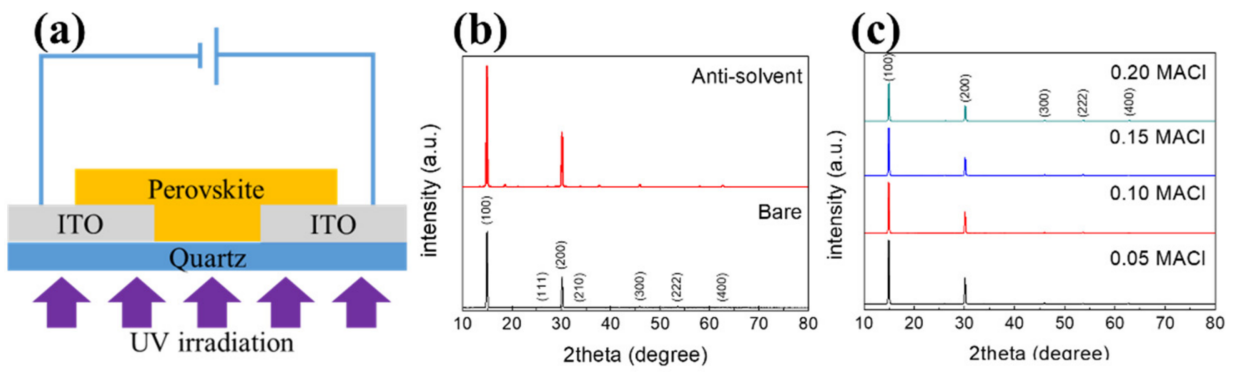

Figure 1. (a) Schematic of the fabricated sample and XRD patterns of $\mathrm{MAPbBr}_{3}$ : (b) bare and antisolvent-processed, (c) with 0.05, 0.10, 0.15, and 0.20 M added MACl.

\subsection{Characterization and Device Measurement}

The shape and microstructure of the synthesized perovskite layer were investigated by field-emission scanning electron microscopy (FE-SEM, S-4700, Hitachi, Tokyo, Japan) and X-ray diffractometry (XRD, D/MAX-2200, Rigaku, Tokyo, Japan) at the Smart Materials Research Center for IoT of Gachon University. The electrical properties of the devices were measured using a UV-visible (UV-vis) spectrometer (UV-Vis 8453, Agilent, Santa Clara, CA, USA). The electrical properties of the devices were examined using a semiconducting characterization system (2400 Sourcemeter, Keithley, Cleveland, OH, USA) equipped with a probe station (M 150, Cascade, Beaverton, OR, USA). A 254-nm UV lamp (VL6.LC, Vilber, France) was used as the light source for UV irradiation.

\section{Results and Discussion}

\section{Characteristics of the Prepared Perowskite Film}

The XRD patterns of the bare $\mathrm{MAPbBr}_{3}$ and $\mathrm{MAPbBr}_{3}$ with the antisolvent process are shown in Figure $1 \mathrm{~b}$. The pattern of $\mathrm{MAPbBr}_{3}$ showed sharp diffraction peaks at $2 \theta=14.94^{\circ}$, $26.02^{\circ}, 30.16^{\circ}, 33.92^{\circ}, 45.90^{\circ}, 53.56^{\circ}$, and $62.66^{\circ}$, corresponding to the (100), (111), (200), (210), (300), (222), and (400) planes, respectively [11-13]. The prepared $\mathrm{MAPbBr}_{3}$ thin films show no impurity diffraction peaks and the uniform pure tetragonal phase coatings are formed. The crystallite sizes, calculated using the full widths at half maximum and the 
Debye-Scherrer equation, are approximately 41.9 and $38.1 \mathrm{~nm}$ for the bare and antisolventprocessed samples.

The XRD patterns of the $\mathrm{MAPbBr}_{3}$ thin films with $0.05,0.10,0.15$, and $0.20 \mathrm{M}$ of added $\mathrm{MACl}$ are given in Figure 1c. The sharp peaks corresponding to the (100), (200), and (300) planes in each XRD pattern confirm that the $\mathrm{MAPbBr}_{3}$ thin films with $0.05-0.20 \mathrm{M}$ added $\mathrm{MACl}$ were all in pure phase state. The peaks shifted to larger diffraction angles as the $\mathrm{Cl}$ content increased. The XRD peak of the (100) plane of the MAPbBr3 thin film to which $0.20 \mathrm{M}$ of $\mathrm{MACl}$ was added was shifted from $14.94^{\circ}$ to $14.96^{\circ}$. The measured $\mathrm{d}_{100}$ spacing of the $\mathrm{MAPbBr}_{3}$ thin film decreased from $2.995 \AA$ (at $14.94^{\circ}$ ) to $2.983 \AA$ (at $14.96^{\circ}$ ) with the addition of $\mathrm{MACl}$, owing to the mixing of $\mathrm{Cl}$ with a smaller atomic radius [14-16].

The SEM images of the $\mathrm{MAPbBr}_{3}$ thin film are presented in Figure 2. The cubic shape $\mathrm{MAPbBr}_{3}$ crystal are seen in Figure $2 \mathrm{a}$. The size of the crystals ranged from 5 to $15 \mu \mathrm{m}$. The crystal grains were separated, and because of the one-step coating method, in most cases, the surface was not wholly covered, and the crystal distribution was not uniform $[17,18]$. In Figure 2b, an SEM image is shown for the $\mathrm{MAPbBr}_{3}$ thin film with the antisolvent process. Compared with Figure 2a, the antisolvent-processed $\mathrm{MAPbBr}_{3}$ thin film showed a smooth and pinhole-controlled perovskite surface. The toluene-added $\mathrm{MAPbBr}_{3}$ thin films exhibited superior crystallinity and uniformity compared to the films attained through the conventional spin-coating method. It is known that the uniformity of the perovskite thin film can significantly affect the UV sensor performance $[19,20]$.

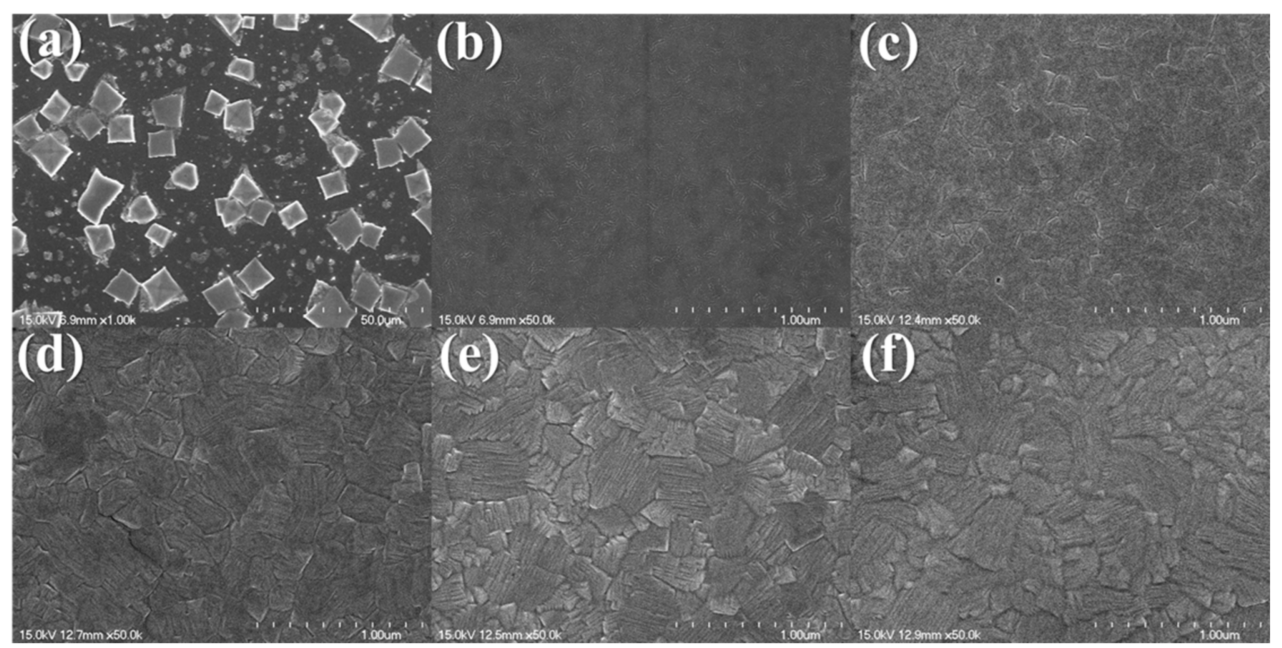

Figure 2. FE-SEM images of $\mathrm{MAPbBr}_{3}$ : (a) bare, (b) antisolvent-processed, and with (c) $0.05 \mathrm{M}$, (d) $0.10 \mathrm{M}$, (e) $0.15 \mathrm{M}$, (f) $0.20 \mathrm{M}$ added $\mathrm{MACl}$.

In Figure 2c-f, the surfaces of the $\mathrm{MAPbBr}_{3}$ thin film with $0.05-0.20 \mathrm{M} \mathrm{MACl}$ are shown. The surfaces of the $\mathrm{MAPbBr}_{3}$ thin films to which $0.05-0.20 \mathrm{M}$ of $\mathrm{MACl}$ are added are thin films with large grain sizes. In Figure $2 a-c$, only relatively small grains were observed. In Figure $2 \mathrm{~d}$,e, the larger grains are observed due to grain growth, while Figure $2 \mathrm{f}$ shows blurry grain boundaries due to degradation from the intense chemical treatment. As the amount of $\mathrm{MACl}$ was increased, the grain size generally increased, while, in the $\mathrm{MAPbBr}_{3}$ thin film containing $0.10 \mathrm{M} \mathrm{MACl}$, the grains of approximately $100 \mathrm{~nm}$ remained. However, large grains of $500 \mathrm{~nm}$ or more were dominant.

The UV-vis absorbance spectrum of the $\mathrm{MAPbBr}_{3}$ thin film is shown in Figure 3a. $\mathrm{MAPbBr}_{3}$ has a strong absorption band in the range of 200-510 $\mathrm{nm}$ [21,22]. Therefore, a UV sensor based on $\mathrm{MAPbBr}_{3}$ has a strong advantage in detecting UV rays in the UVC region. The sharp band edge of $\mathrm{MAPbBr}_{3}$ was clearly observed, indicating the direct bandgap of $\mathrm{MAPbBr}_{3}$. The bandgap of the bare $\mathrm{MAPbBr}_{3}$ was estimated by extrapolating the linear range from $(\mathrm{F}(\mathrm{R} \infty) \mathrm{h} v)^{2}$ to the photon energy $(\mathrm{h} v)$ intercept, depending on estimations by the Tauc and Davis-Mott models $[23,24]$, is $2.27 \mathrm{eV}[25,26]$. The bandgap of the antisolvent- 
processed $\mathrm{MAPbBr}_{3}$ was $2.28 \mathrm{eV}$; the crystal size and the bandgap of the film decreased and increased, respectively, compared to those of the bare film. This is because the electron-hole pairs were much closer with non-negligible Coulomb interactions, resulting in a higher overall kinetic energy [27]. The bandgaps of $\mathrm{MAPbBr}_{3}$ with $0.05-0.20 \mathrm{M}$ added $\mathrm{MACl}$ increased as the concentration of $\mathrm{MACl}$ increased.
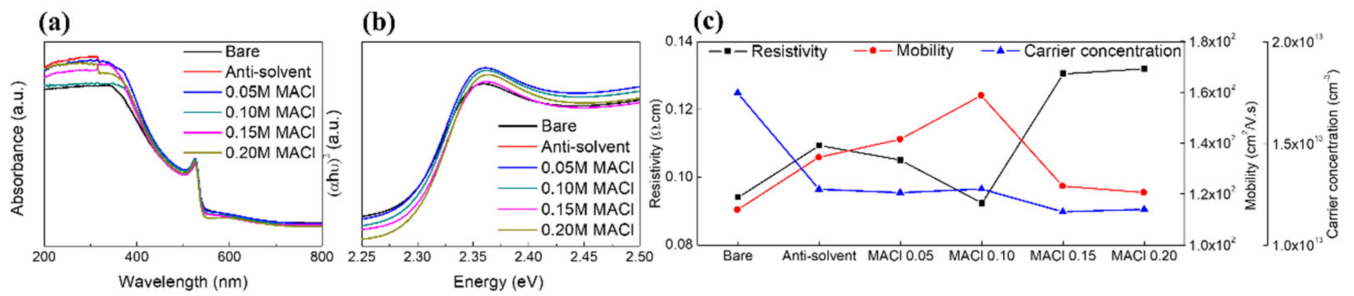

Figure 3. (a) UV-vis absorbance of $\mathrm{MAPbBr}_{3}$, (b) dependence of absorption of the photon energy, (c) electrical characteristics of $\mathrm{MAPbBr}_{3}$.

The electrical characteristics of the $\mathrm{MAPbBr}_{3}$ thin films are shown in Figure $3 \mathrm{c}$. The electrical characteristics, including the semiconductor type, resistivity, carrier concentration and mobility were determined using the Hall measurements. From the measurements, it was confirmed that all $\mathrm{MAPbBr}_{3}$ thin films had carrier concentrations of more than $10^{13} \mathrm{~cm}^{-3}$ and p-type characteristics. The resistivity values were 0.0941 and $0.1094 \Omega \cdot \mathrm{cm}$ for the bare and antisolvent-processed $\mathrm{MAPbBr}_{3}$ thin films, and those for the $\mathrm{MAPbBr}_{3}$ films with $0.05,0.10,0.15$, and $0.20 \mathrm{M} \mathrm{MACl}$ were $0.1051,0.0924,0.1306$, and $0.1320 \Omega \cdot \mathrm{cm}$, respectively. The mobilities were 113.8, 134.4, 141.5, 158.7, 123.1 and $120.6 \mathrm{~cm}^{2} / \mathrm{V} \cdot \mathrm{s}$ for bare $\mathrm{MAPbBr}_{3}$, antisolvent-processed $\mathrm{MAPbBr}_{3}$, and $\mathrm{MAPbBr}_{3}$ with $0.05,0.10,0.15$, and $0.20-\mathrm{M}$ added $\mathrm{MACl}$, respectively. The mobility increased as the amount of $\mathrm{MACl}$ was increased to $0.10 \mathrm{M}$, while it decreased for amounts exceeding $0.10 \mathrm{M}$. This was attributed to the increase in the diffusion distance and the decrease in the trap density with the addition of MACl. [28] The diffusion coefficient can be specified using the Einstein equation $\left(D=\frac{\mu K_{B} T}{q}\right.$, where $K_{B}$ is the Boltzmann constant, $T$ is the temperature of the sample, and $q$ is the amount of charge). Because the diffusion coefficient is proportional to the diffusion distance, a higher mobility can lead to an increased diffusion distance.

To analyze the UVC detection characteristics, a series of sensor structures were fabricated and compared using bare $\mathrm{MAPbBr}_{3}$, antisolvent-processed $\mathrm{MAPbBr}_{3}$, and $\mathrm{MAPbBr}_{3}$ with $0.05-0.20 \mathrm{M} \mathrm{MACl}$ thin films deposited on the etched ITO. The current-voltage $(I-V)$ curves of the $\mathrm{MAPbBr}_{3}$-based sensors are displayed in Figure 4 . The $I-V$ characteristics were measured by switching the bias voltage from $-2 \mathrm{~V}$ to $2 \mathrm{~V}$ at a scan rate of $0.1 \mathrm{~V}$ in a dark room where light was blocked and under a 254-nm light source with $1.02 \mathrm{~mW} / \mathrm{cm}^{2}$ output.

The coated perovskite formed a Schottky barrier owing to contact with the ITO electrode. Under the applied voltage, ion movement and carrier trapping in the active region occurred at the ITO/perovskite interface. This indicated that an ohmic contact was formed between the perovskite and ITO electrodes. For all samples, an apparent increase in current was detected under the $254 \mathrm{~nm}$ light at $1.02 \mathrm{~mW} / \mathrm{cm}^{2}$. The $I-V$ curves obtained under the $254 \mathrm{~nm}$ irradiation maintained rectified shapes even with the addition of various concentrations of $\mathrm{MACl}$. In this measurement, the $\mathrm{MAPbBr}_{3}$ films with the addition of $\mathrm{MACl}$ showed that a significant photocurrent could be photogenerated.

The reactivity $(R)$ and specific detectivity $\left(D^{*}\right)$ are the main parameters used to evaluate the UV sensors. $R$, which reflects the sensor response to incident light, is determined as $R=\left(I_{\text {light }}-I_{\text {dark }}\right) / A P_{\text {op }}$, where $I_{\text {light }}$ is the photocurrent under 254-nm UV light, $I_{\text {dark }}$ is the dark current, $A$ is the active area of the sensor and $P_{\text {op }}$ is the incident light power $[29,30]$. The detectivity $D^{*}$ reflects the performance of the sensor, which can be checked by the performance of the signal generated by the main noise and light source in the dark [31,32]. $D^{*}$ is expressed as $D^{*}=R /\left(2 q J_{\text {dark }}\right)$, where $q$ is the amount of charge and $J_{\text {dark }}$ is the dark current density. 
(a)



(c)

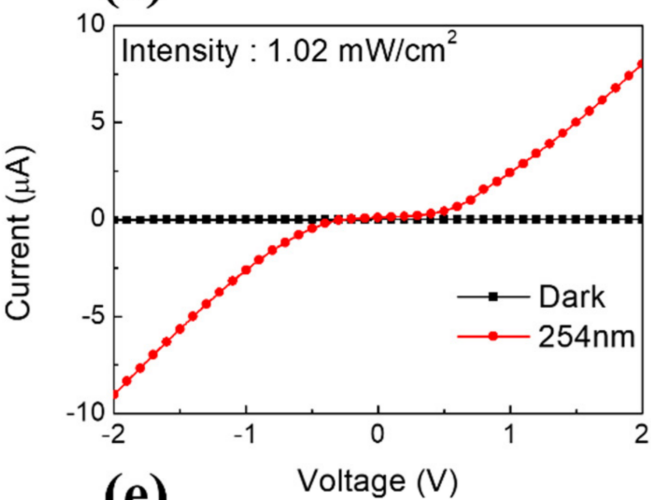

(e)

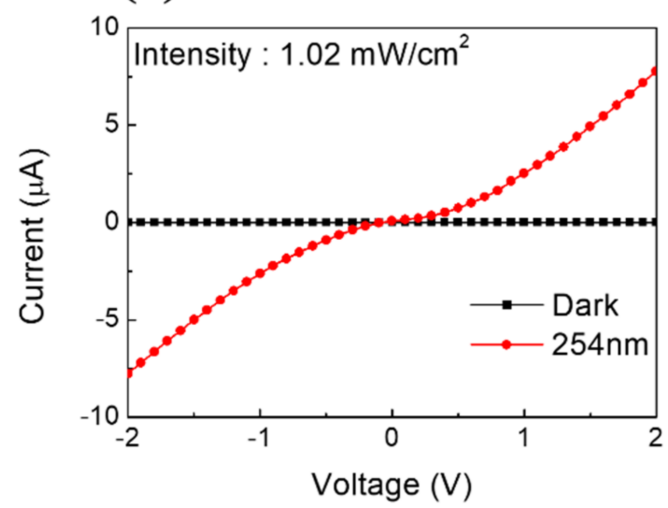

(b)
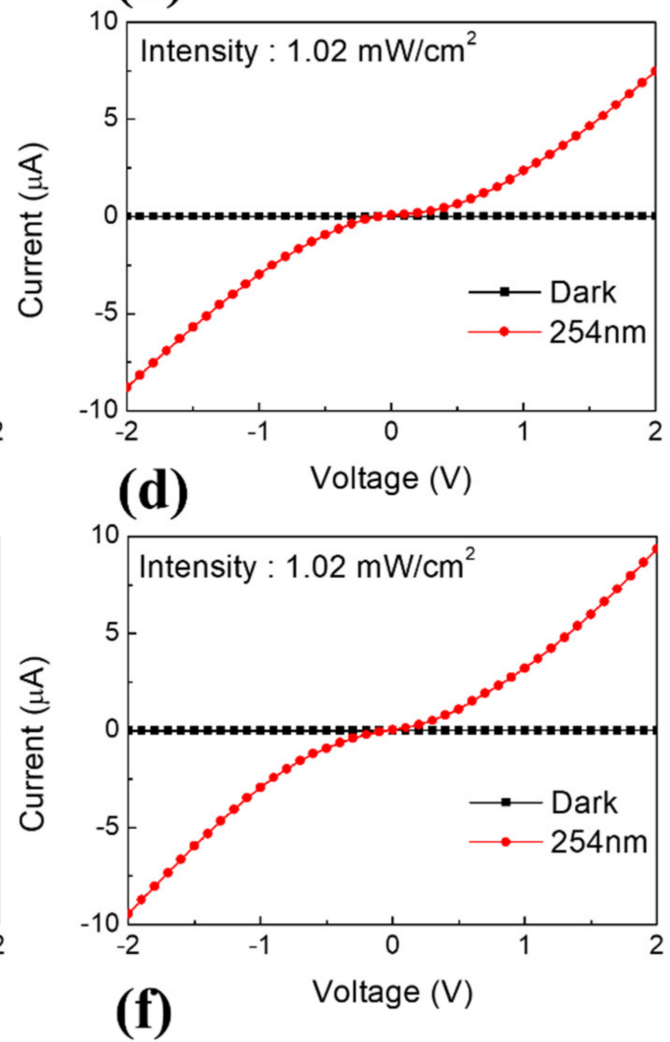

(f)

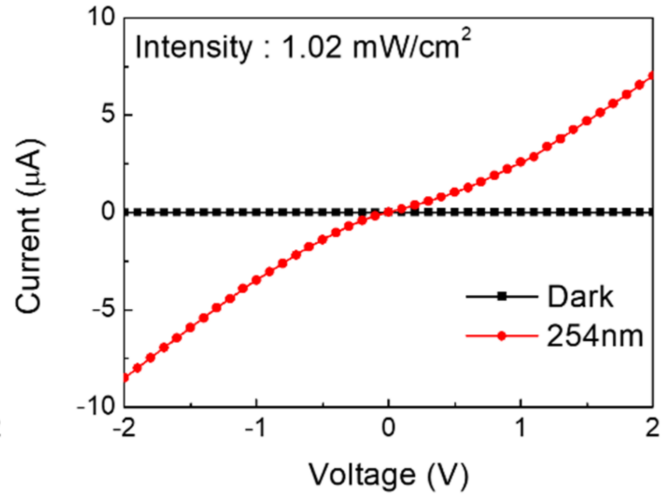

Figure 4. Current-voltage (I-V) characteristics of perovskite-based UV sensors. (a) Bare, (b) antisolventprocessed, and containing (c) 0.05-M MACl, (d) 0.10-M MACl, (e) 0.15-M MACl, (f) 0.20-M MACl.

In Figure $5 \mathrm{a}$, the responsivity curves of the $\mathrm{MAPbBr}_{3}$-based sensors are given. The responsivity curves showed that the value of $R$ gradually increased as the bias voltage increased from 0 to $2 \mathrm{~V}$. This was attributed to the increase in the conversion efficiency of the photodetector from photons to charge. At the bias voltage of $2 \mathrm{~V}$ under the 254-nm illumination at $1.02 \mathrm{~mW} / \mathrm{cm}^{2}$, the $R$ values were $2.00,3.65,3.91,4.57,3.79$ and $3.43 \mathrm{~mA} / \mathrm{W}$ for bare, antisolvent-processed, 0.05-, 0.10-, 0.15- and 0.20-M MACl-added $\mathrm{MAPbBr}_{3}$, respectively.

The detectivity curves of $\mathrm{MAPbBr}_{3}$ with added $\mathrm{MACl}$ are shown in Figure $5 \mathrm{~b}$. Under an applied $2 \mathrm{~V}$ bias voltage, the $D^{*}$ values were $2.13 \times 10^{12}$ and $1.49 \times 10^{12}$ for bare and antisolvent-processed $\mathrm{MAPbBr}_{3}$. The $D^{*}$ values were $7.14 \times 10^{12}, 1.02 \times 10^{13}, 7.28 \times 10^{12}$, and $4.11 \times 10^{12}$ for $\mathrm{MAPbBr}_{3}$ with $0.05,0.10,0.15$, and $0.20 \mathrm{M}$ of added $\mathrm{MACl}$. Because $D^{*}$ depends on the dark current value, it is strongly influenced by the noise generated in measuring the dark current. 
(a)



(c)

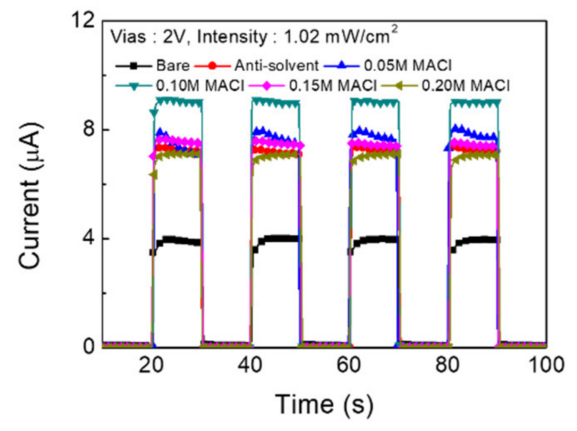

(b)

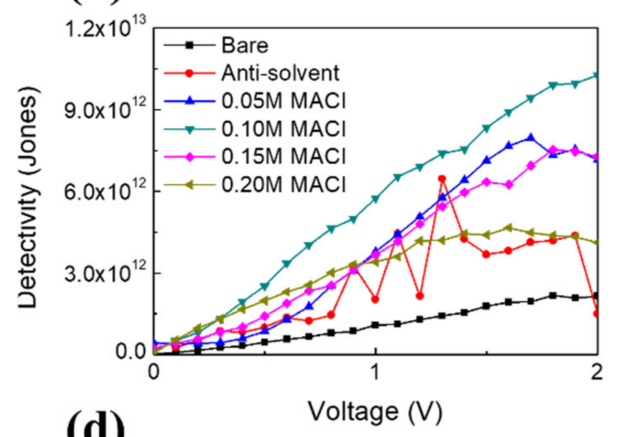

(d)

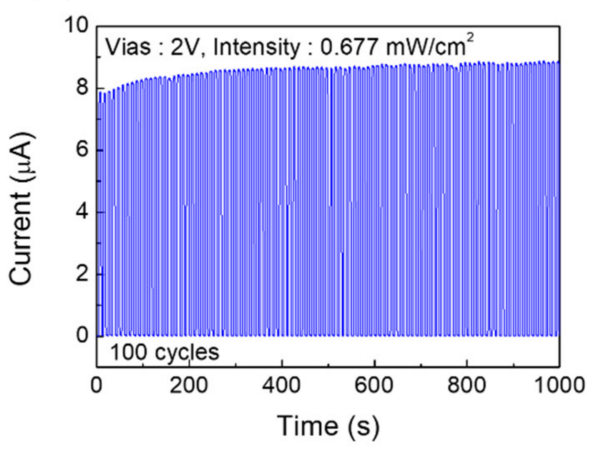

Figure 5. (a) Responsivity curves of $\mathrm{MAPbBr}_{3}$ sensors, (b) detectivity curves of $\mathrm{MAPbBr}_{3}$ sensors, (c) transient photoresponses, (d) stability of the prepared device for $100 \mathrm{ON} / \mathrm{OFF}$ switching cycles under the illumination of 254-nm light with an intensity of $0.677 \mathrm{~mW} / \mathrm{cm}^{2}$.

The EQE, another determinant of sensor performance, is defined as the number of electrons generated per incident photon [33-35], as follows: EQE $=R h c / e \lambda$, where $h$ is Planck's constant, $c$ is the speed of light, and $\lambda$ is the wavelength of the incident light. At $2 \mathrm{~V}$, EQEs were $9.77 \%$ and $17.84 \%$ for the bare and antisolvent-processed $\mathrm{MAPbBr}_{3}$, and $19.13 \%, 22.32 \%, 18.55 \%$ and $16.76 \%$ for $\mathrm{MAPbBr}_{3}$ with $0.05,0.10,0.15$ and $0.20 \mathrm{M}$ of added $\mathrm{MACl}$, respectively.

In Figure $5 \mathrm{c}$, the time-dependent photoresponses are shown for $\mathrm{MAPbBr}_{3}$-based sensors measured at a bias voltage of $2 \mathrm{~V}$ and power intensity of $1.02 \mathrm{~mW} / \mathrm{cm}^{2}$. The response time reflects the capacity of the photodetector to follow rapidly changing optical signals. The rise and fall times characterize the response speed of a light detector, and they are usually defined as the time intervals required for the photocurrent to rise, or fall, from 10 to $90 \%$ of its peak value, or vice versa. All fabricated samples showed excellent response characteristics, with rise/fall times of $32.6 \mathrm{~ms} / 32.1 \mathrm{~ms}$ and $30 \mathrm{~ms} / 28 \mathrm{~ms}$ for bare and antisolvent-processed $\mathrm{MAPbBr}_{3}$ and $29.8 \mathrm{~ms} / 29 \mathrm{~ms}, 15.8 \mathrm{~ms} / 16.2 \mathrm{~ms}, 25.8 \mathrm{~ms} / 32.1 \mathrm{~ms}$, and $35.1 \mathrm{~ms} / 39 \mathrm{~ms}$ for $\mathrm{MAPbBr}_{3}$ with $0.05,0.10,0.15$, and $0.20-\mathrm{M}$ added $\mathrm{MACl}$, respectively.

The ON/OFF repeatability of the operation of a sensor using an $\mathrm{MAPbBr}_{3}$ thin film with $0.10 \mathrm{M}$ of added $\mathrm{MACl}$ under a 254-nm light source with $0.677 \mathrm{~mW} / \mathrm{cm}^{2}$ output is given in Figure 5d. The sensor was irradiated for $5 \mathrm{~s}$. The tested sensor showed reproducibility with consistent performance over $100 \mathrm{ON} / \mathrm{OFF}$ iterations. In the first iteration, the photocurrent was $7.06 \mu \mathrm{A}$; and after 100 repetitions was $8.78 \mu \mathrm{A}$. This shows that the reproducibility was maintained continuously relative to the initial photocurrent.

The parameters of the simply structured perovskite-based UVC detector developed in this study are similar to those of the photodetectors reported in other studies (Table 1). Compared to previously reported photodetectors, the proposed detector can be manufactured with a simple structure using a solution process at a low temperature, and it shows high-performance detection. 
Table 1. Comparison of important parameters of various UV detectors.

\begin{tabular}{|c|c|c|c|c|c|c|}
\hline Materials & $\begin{array}{l}\text { Light } \\
(\mathrm{nm})\end{array}$ & Method & $\begin{array}{c}\text { Voltage } \\
\text { (V) }\end{array}$ & $\begin{array}{l}\text { Responsivity } \\
\text { (mA/W) }\end{array}$ & $\begin{array}{c}\text { Detectivity } \\
\text { (Jones) }\end{array}$ & $\begin{array}{l}\text { EQE } \\
(\%)\end{array}$ \\
\hline $\begin{array}{c}\mathrm{CH}_{3} \mathrm{NH}_{3} \mathrm{PbBr}_{3} \\
\text { [this study] }\end{array}$ & 254 & Solution & 2 & 4.57 & $1.02 \times 10^{13}$ & 22.2 \\
\hline $\begin{array}{c}\mathrm{CH}_{3} \mathrm{NH}_{3} \mathrm{PbCl}_{3} \\
{[36]}\end{array}$ & 255 & Single crystals & 5 & 450 & - & 219 \\
\hline $\begin{array}{c}\mathrm{CH}_{3} \mathrm{NH}_{3} \mathrm{PbBr}_{3} \\
{[36]}\end{array}$ & 255 & Single crystals & 5 & 300 & - & 146 \\
\hline $\begin{array}{c}\mathrm{CH}_{3} \mathrm{NH}_{3} \mathrm{PbI}_{3} \\
{[36]}\end{array}$ & 255 & Single crystals & 5 & 120 & - & 58 \\
\hline $\begin{array}{c}\mathrm{CH}_{3} \mathrm{NH}_{3} \mathrm{PbCl}_{3} \\
{[37]}\end{array}$ & 365 & Single crystals & 15 & 46.90 & $1.2 \times 10^{10}$ & - \\
\hline $\begin{array}{c}\mathrm{Ga}_{2} \mathrm{O}_{3} \\
{[38]}\end{array}$ & 185 & MOCVD * & 10 & 0.3 & $2.8 \times 10^{10}$ & 0.2 \\
\hline $\begin{array}{c}\mathrm{CsPbBr}_{3}-\mathrm{Cs}_{4} \mathrm{PbBr}_{6} \\
{[39]}\end{array}$ & 254 & Vapor & 0 & 49.40 & $1.2 \times 10^{12}$ & 31 \\
\hline $\begin{array}{c}\mathrm{CH}_{3} \mathrm{NH}_{3} \mathrm{PbCl}_{3} \\
{[40]}\end{array}$ & 398 & Solution & -1 & 71 & $1.2 \times 10^{10}$ & 23 \\
\hline
\end{tabular}

* Metal-organic chemical vapor deposition.

\section{Conclusions}

In summary, a simply structured perovskite-based optical sensor was fabricated through a low-temperature solution process. It showed a fast response speed (rise/fall time) of $15.8 / 16.2 \mathrm{~ms}$, mobility of $158.7 \mathrm{~cm}^{2} / \mathrm{V} \cdot \mathrm{s}$, responsivity of $4.57 \mathrm{~mA} / \mathrm{W}$, detectivity of $1.02 \times 10^{13}$ Jones, and EQE of $22.32 \%$. Therefore, the sensor reported in this study provides a promising solution for UVC detection.

Author Contributions: Investigation, S.G.S.; Supervision, H.W.C.; Validation, C.W.B. and H.W.C.; Writing—original draft, S.G.S.; Writing-review \& editing, C.W.B. and H.W.C. All authors have read and agreed to the published version of the manuscript.

Funding: This research was supported by the Basic Science Research Capacity Enhancement Project through a Korea Basic Science Institute (National Research Facilities and Equipment Center) grant funded by the Ministry of Education (2019R1A6C1010016). This work was supported by the Korea Institute of Energy Technology Evaluation and Planning (KETEP) and the Ministry of Trade, Industry \& Energy (MOTIE) of the Republic of Korea (No. 20194030202290).

Institutional Review Board Statement: Not applicable.

Informed Consent Statement: Not applicable.

Data Availability Statement: Not applicable.

Conflicts of Interest: The authors declare no conflict of interest.

\section{References}

1. Boggess, A.; Carr, F.A.; Evans, D.C.; Fischel, D.; Freeman, H.R.; Fuechsel, C.F.; Klinglesmith, D.A.; Krueger, V.L.; Longanecker, G.W.; Moore, J.V.; et al. The IUE spacecraft and instrumentation. Nat. Cell Biol. 1978, 275, 372-377. [CrossRef]

2. Xu, Z.; Ding, H.; Sadler, B.M.; Chen, G. Analytical performance study of solar blind non-line-of-sight ultraviolet short-range communication links. Opt. Lett. 2008, 33, 1860-1862. [CrossRef]

3. Lin, R.; Zheng, W.; Zhang, D.; Zhang, Z.; Liao, Q.; Yang, L.; Huang, F. High-performance graphene $/ \beta-\mathrm{Ga}_{2} \mathrm{O}_{3}$ heterojunction deep-ultraviolet photodetector with hot-electron excited carrier multiplication. ACS Appl. Mater. Interfaces 2018, 10, 22419-22426. [CrossRef] [PubMed]

4. Zheng, W.; Lin, R.; Ran, J.; Zhang, Z.; Ji, X.; Huang, F. Vacuum-Ultraviolet Photovoltaic Detector. ACS Nano 2018, 12 , 425-431. [CrossRef] [PubMed]

5. Zheng, W.; Lin, R.; Zhang, Z.; Huang, F. Vacuum-Ultraviolet Photodetection in Few-Layered h-BN. ACS Appl. Mater. Interfaces 2018, 10, 27116-27123. [CrossRef] [PubMed]

6. Gökkavas, M.; Butun, S.; Caban, P.; Strupinski, W.; Ozbay, E. Integrated AlGaN quadruple-band ultraviolet photodetectors. Semicond. Sci. Technol. 2012, 27, 065004. [CrossRef] 
7. Ju, Z.G.; Shan, C.X.; Jiang, D.Y.; Zhang, J.Y.; Yao, B.; Zhao, D.X.; Shen, D.Z.; Fan, X.W. Mg $\mathrm{Zn}_{1-\mathrm{x}} \mathrm{O}$-based photodetectors covering the whole solar-blind spectrum range. Appl. Phys. Lett. 2008, 93, 173505. [CrossRef]

8. Mendoza, F.; Makarov, V.; Weiner, B.R.; Morell, G. Solar-blind field-emission diamond ultraviolet detector. Appl. Phys. Lett. 2015, 107, 201605. [CrossRef]

9. Chen, H.; Liu, H.; Zhang, Z.; Hui, L.; Fang, X. Nanostructured Photodetectors: From Ultraviolet to Terahertz. Adv. Mater. 2016, 28, 403-433. [CrossRef]

10. Zhang, D.; Zheng, W.; Lin, R.; Li, T.; Zhang, Z.; Huang, F. High quality $\beta-\mathrm{Ga}_{2} \mathrm{O}_{3}$ film grown with N2O for high sensitivity solar-blind-ultraviolet photodetector with fast response speed. J. Alloys Compd. 2018, 735, 150-154. [CrossRef]

11. Zhumekenov, A.A.; Burlakov, V.M.; Saidaminov, M.I.; Alofi, A.; Haque, A.; Turedi, B.; Davaasuren, B.; Dursun, I.; Cho, N.; El-Zohry, A.M.; et al. The Role of Surface Tension in the Crystallization of Metal Halide Perovskites. ACS Energy Lett. 2017, 2, 1782-1788. [CrossRef]

12. Tisdale, J.T.; Smith, T.; Salasin, J.R.; Ahmadi, M.; Johnson, N.; Ievlev, A.V.; Koehler, M.; Rawn, C.J.; Lukosi, E.; Hu, B. Precursor purity effects on solution-based growth of $\mathrm{MAPbBr}_{3}$ single crystals towards efficient radiation sensing. CrystEngComm 2018, 20, 7818-7825. [CrossRef]

13. Saidaminov, M.I.; Abdelhady, A.L.; Murali, B.; Alarousu, E.; Burlakov, V.M.; Peng, W.; Dursun, I.; Wang, L.; He, Y.; Maculan, G.; et al. High-quality bulk hybrid perovskite single crystals within minutes by inverse temperature crystallization. Nat. Commun. 2015, 6, 7586. [CrossRef]

14. Wang, L.; Yuan, G.D.; Duan, R.F.; Huang, F.; Wei, T.B.; Liu, Z.Q.; Wang, J.X.; Li, J.M. Tunable bandgap in hybrid perovskite $\mathrm{CH}_{3} \mathrm{NH}_{3} \mathrm{~Pb}\left(\mathrm{Br}_{3-\mathrm{y}} \mathrm{X}\right)$ single crystals and photodetector applications. AIP Adv. 2016, 6, 045115. [CrossRef]

15. Senocrate, A.; Kim, G.Y.; Grätzel, M.; Maier, J. Thermochemical stability of hybrid halide perovskites. ACS Energy Lett. 2019, 4, 2859-2870. [CrossRef]

16. Lu, H.; Zhang, H.; Yuan, S.; Wang, J.; Zhan, Y.; Zheng, L. An optical dynamic study of $\mathrm{MAPbBr}_{3}$ single crystals passivated with $\mathrm{MAPbCl}_{3} / \mathrm{I}_{3}-\mathrm{MAPbBr}_{3}$ heterojunctions. Phys. Chem. Chem. Phys. 2017, 19, 4516-4521. [CrossRef]

17. Mhamdi, A.; Mehdi, H.; Bouazizi, A.; Garcia-Belmonte, G. One-step methylammonium lead bromide films: Effect of annealing treatment. J. Mol. Struct. 2019, 1192, 1-6. [CrossRef]

18. Tidhar, Y.; Edri, E.; Weissman, H.; Zohar, D.; Hodes, G.; Cahen, D.; Rybtchinski, B.; Kirmayer, S. Crystallization of methyl ammonium lead halide perovskites: Implications for photovoltaic applications. J. Am. Chem. Soc. 2014, 136, 13249-13256. [CrossRef] [PubMed]

19. Dualeh, A.; Tétreault, N.; Moehl, T.; Gao, P.; Nazeeruddin, M.K.; Grätzel, M. Effect of Annealing Temperature on Film Morphology of Organic-Inorganic Hybrid Pervoskite Solid-State Solar Cells. Adv. Funct. Mater. 2014, 24, 3250-3258. [CrossRef]

20. Eperon, G.E.; Burlakov, V.M.; Docampo, P.; Goriely, A.; Snaith, H.J. Morphological Control for High Performance, SolutionProcessed Planar Heterojunction Perovskite Solar Cells. Adv. Funct. Mater. 2014, 24, 151-157. [CrossRef]

21. Mehdi, H.; Mhamdi, A.; Hannachi, R.; Bouazizi, A. MAPbBr 3 perovskite solar cells via a two-step deposition process. RSC Adv. 2019, 9, 12906-12912. [CrossRef]

22. Chen, L.C.; Wu, J.R.; Tseng, Z.L.; Chen, C.C.; Chang, S.H.; Huang, J.K.; Lee, K.L.; Cheng, H.M. Annealing effect on (FAPbI $\left.)_{3}\right)_{1-x}$ $\left(\mathrm{MAPbBr}_{3}\right)_{\mathrm{x}}$ perovskite films in inverted-type perovskite solar cells. Materials 2016, 9, 747. [CrossRef]

23. Tauc, J.; Grigorovici, R.; Vancu, A. Optical Properties and Electronic Structure of Amorphous Germanium. Phys. Status Solidi (b) 1966, 15, 627-637. [CrossRef]

24. Davis, E.A.; Mott, N. Conduction in non-crystalline systems V. Conductivity, optical absorption and photoconductivity in amorphous semiconductors. Philos. Mag. 1970, 22, 0903-0922. [CrossRef]

25. Wang, K.-H.; Li, L.-C.; Shellaiah, M.; Sun, K.W. Structural and Photophysical Properties of Methylammonium Lead Tribromide $\left(\mathrm{MAPbBr}_{3}\right)$ Single Crystals. Sci. Rep. 2017, 7, 1-14. [CrossRef]

26. Kong, L.; Liu, G.; Gong, J.; Hu, Q.; Schaller, R.D.; Dera, P.; Tang, Y. Simultaneous band-gap narrowing and carrier-lifetime prolongation of organic-inorganic trihalide perovskites. Proc. Natl. Acad. Sci. USA 2016, 113, 8910-8915. [CrossRef]

27. Singh, M.; Goyal, M.; Devlal, K. Size and shape effects on the band gap of semiconductor compound nanomaterials. J. Taibah Univ. Sci. 2018, 12, 470-475. [CrossRef]

28. Xie, F.X.; Su, H.; Mao, J.; Wong, K.S.; Choy, W.C.H. Evolution of Diffusion Length and Trap State Induced by Chloride in Perovskite Solar Cell. J. Phys. Chem. C 2016, 120, 21248-21253. [CrossRef]

29. Yu, J.; Javaid, K.; Liang, L.; Wu, W.; Liang, Y.; Song, A.; Cao, H. High-performance visible-blind ultraviolet photodetector based on IGZO TFT coupled with p-n heterojunction. ACS Appl. Mater. Interfaces 2018, 10, 8102-8109. [CrossRef] [PubMed]

30. Cai, J.; Chen, X.; Hong, R.; Yang, W.; Wu, Z. High-performance 4H-SiC-based pin ultraviolet photodiode and investigation of its capacitance characteristics. Opt. Commun. 2014, 333, 182-186. [CrossRef]

31. Inamdar, S.; Ganbavle, V.; Shaikh, S.; Rajpure, K. Effect of the buffer layer on the metal-semiconductor-metal UV photodetector based on Al-doped and undoped $\mathrm{ZnO}$ thin films with different device structures. Phys. Status Solidi (A) 2015, 212, 1704-1712. [CrossRef]

32. Singh, S. Al doped $\mathrm{ZnO}$ based metal-semiconductor-metal and metal-insulator-semiconductor-insulator-metal UV sensors. Optik 2016, 127, 3523-3526. [CrossRef] 
33. Li, S.; Yan, Z.; Liu, Z.; Chen, J.; Zhi, Y.; Guo, D.; Li, P.; Wu, Z.; Tang, W. A self-powered solar-blind photodetector with large V oc enhancing performance based on the PEDOT:PSS $/ \mathrm{Ga}_{2} \mathrm{O}_{3}$ organic-inorganic hybrid heterojunction. J. Mater. Chem. C 2020, 8 , 1292-1300. [CrossRef]

34. Kim, J.O.; Sengupta, S.; Barve, A.V.; Sharma, Y.D.; Adhikary, S.; Lee, S.J.; Noh, S.K.; Allen, M.S.; Allen, J.W.; Chakrabarti, S.; et al. Multi-stack InAs/InGaAs sub-monolayer quantum dots infrared photodetectors. Appl. Phys. Lett. 2013, 102, 011131. [CrossRef]

35. Chen, J.-H.; Jing, Q.; Xu, F.; Lu, Z.-D.; Lu, Y.-Q. High-sensitivity optical-fiber-compatible photodetector with an integrated CsPbBr_3-graphene hybrid structure. Optica 2017, 4, 835-838. [CrossRef]

36. Zhang, Z.; Zheng, W.; Lin, R.; Huang, F. High-sensitive and fast response to $255 \mathrm{~nm}$ deep-UV light of $\mathrm{CH}_{3} \mathrm{NH}_{3} \mathrm{PbX} 3(\mathrm{X}=\mathrm{Cl}, \mathrm{Br}, \mathrm{I})$ bulk crystals. R. Soc. Open Sci. 2018, 5, 180905. [CrossRef]

37. Maculan, G.; Sheikh, A.D.; Abdelhady, A.L.; Saidaminov, M.I.; Haque, A.; Murali, B.; Alarousu, E.; Mohammed, O.F.; Wu, T.; Bakr, O.M. $\mathrm{CH}_{3} \mathrm{NH}_{3} \mathrm{PbCl}_{3}$ Single Crystals: Inverse Temperature Crystallization and Visible-Blind UV-Photodetector. J. Phys. Chem. Lett. 2015, 6, 3781-3786. [CrossRef] [PubMed]

38. Wei, T.C.; Tsai, D.S.; Ravadgar, P.; Ke, J.J.; Tsai, M.L.; Lien, D.H.; Huang, C.Y.; Horng, R.H.; He, J.H. See-Through Ga $2 \mathrm{O}_{3}$ Solar-Blind Photodetectors for Use in Harsh Environments. IEEE J. Sel. Top. Quantum Electron. 2014, 20, $112-117$.

39. Tong, G.; Li, H.; Zhu, Z.; Zhang, Y.; Yu, L.; Xu, J.; Jiang, Y. Enhancing Hybrid Perovskite Detectability in the Deep Ultraviolet Region with Down-Conversion Dual-Phase $\left(\mathrm{CsPbBr}_{3}-\mathrm{Cs}_{4} \mathrm{PbBr}_{6}\right)$ Films. J. Phys. Chem. Lett. 2018, 9, 1592-1599. [CrossRef] [PubMed]

40. Zheng, E.; Yuh, B.; Tosado, G.A.; Yu, Q. Solution-processed visible-blind UV-A photodetectors based on $\mathrm{CH}_{3} \mathrm{NH}_{3} \mathrm{PbCl}_{3}$ perovskite thin films. J. Mater. Chem. C 2017, 5, 3796-3806. [CrossRef] 